\title{
Analysis on PVT test and empirical formula of Bohai heavy oil with different types of dissolved gases
}

\author{
Yigang Liu ${ }^{1}$ Yingzhong Yuan ${ }^{2}$ (D) Fayuan Zhou ${ }^{1} \cdot{\text { Zhilin } \mathrm{Qi}^{2} \cdot \text { Wei Zhang }}^{1} \cdot$ Hua Zhang ${ }^{1} \cdot$ Qiuxia Wang $^{1}$
}

Received: 28 May 2020 / Accepted: 4 August 2020 / Published online: 10 August 2020

(c) The Author(s) 2020

\begin{abstract}
Accurate prediction of PVT properties of heavy oil system is of great significance to the design of injection-production parameters and dynamic analysis of multi-thermal fluid stimulation in heavy oil reservoir. The saturation pressure and viscosity of Bohai heavy oil system at different temperature and different gas oil ratio conditions were tested and analyzed. The functional relations of regression equations for saturation pressure and viscosity are constructed based on classical PVT correlations, but the parameters in the equations different from classical correlations are obtained from present experiment test data with multiple regression method. The empirical formula analysis results indicate that the 2-parameter equation can almost completely fit the experimental data, but its application scope is narrow. Although the 4-parameter equation has an extensive adaptability, its fitting accuracy is very low. The 3-parameter equation can not only better fit the saturation pressure and viscosity of heavy oil for the same gas under different dissolved gas oil ratios and different temperatures, but also has a wide application range. It is recommended to use the 3-parameter equation for physical property analysis and calculation of heavy oil. The research results provide a basis for the accurate prediction of heavy oil PVT parameters.
\end{abstract}

Keywords Heavy oil $\cdot$ Dissolved gas oil ratio $\cdot$ Saturation pressure $\cdot$ Viscosity $\cdot$ Empirical formula

\section{Introduction}

The heavy oil reservoirs have wide distributions in the world. It is very difficult to develop the heavy oil reservoirs because of extra high viscosity. The horizontal well multithermal fluid stimulation technology is an important way to enhance heavy oil production rate and recovery, especially for the offshore heavy oil reservoir influenced by the factors including limited platform space, economic benefit, environment pollution and operation security (Dong et al. 2014, 2016; Ge et al. 2019; Liu et al. 2020). This technology can effectively increase the production rate of heavy oil by huff and puff or displacement with multi-thermal fluid (Liu et al. 2010; Sun et al. 2011; Hou et al. 2016). Heating and dissolving to reduce viscosity, aquathermal cracking reaction, increasing swept volume, developing hot fluid

Yingzhong Yuan

yuanyingzh0001@ 126.com

CNOOC Tianjin Branch, Tianjin 300459, China

2 Chongqing Key Laboratory of Complex Oil and Gas Fields Exploration and Development, Chongqing University of Science and Technology, Chongqing 401331, China chamber, forming non-miscible displacement, reducing heat loss and maintaining pressure are the important mechanisms of enhancing oil recovery by multi-thermal fluids (Liu et al. 2012; Huang et al. 2018; Wang et al. 2019).

Multi-thermal fluid is a mixture of injection water and high temperature and high pressure gas generated by combustion of diesel and air. Multi-thermal fluid is mainly composed of steam, hot water, $\mathrm{CO}_{2}, \mathrm{~N}_{2}$, etc. (Hou et al. 2016). Among them, $\mathrm{N}_{2}$ and $\mathrm{CO}_{2}$ are two important noncondensable gases. Both of them can be dissolved in heavy oil and play the role of dissolving, reducing viscosity and improving the steam dryness, but their dissolving abilities in heavy oil are not the same (Li et al. 2010, 2017). Generally speaking, the solubility of gas in heavy oil is affected by composition, pressure and temperature of heavy oil and gas. At low temperature condition, PVT properties of heavy oil are mainly influenced by gas solubility. As temperature increases, the influences of heating effect are more obvious (Chen et al. 2018). Within a certain range of pressure and temperature, both gas dissolution and heating have important influences. At present, many scholars have done a large number of experimental tests on the physical properties of heavy oil under high temperature

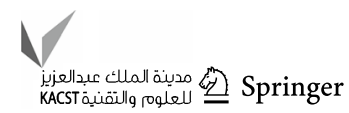


and high pressure conditions, but the existing empirical formulae are not adaptable enough to meet the test results (Sidrouhou and Korichi 2013; Nourozieh et al. 2016; Izurieta and Iza 2017). In order to get more accurate results, some advanced mathematical methods including genetic programming algorithm and neural network models are used to predict oil PVT properties (Fattah 2014; Rammay and Abdulraheem 2017). Because of the complexity of algorithm and uncertainty of model, these methods have not been widely used in prediction of oil PVT properties. In many commercial software, oil PVT properties are usually predicted through interpolation method, especially the prediction points are within the range of existing data. If the prediction points are out of the range, the interpolation method will generate obvious error, and the empirical formulas verified by experimental data has better application effect.

The classical empirical formulas including Standing (1947), Glaso (1980), Vasquez and Beggs (1980) and AlMarhoun (1988) are widely used to predict PVT properties of oil and gas system. Although these formulas have a certain application scope, they are all regression analysis of specific samples, and are often difficult to be extended to other oil-gas systems in other oil fields. The application effect can often be improve if the functional relation of classical empirical formula remains unchanged, but the coefficient of formula is determined according to specific samples (Petrosky and Farshad 1993; Omar and Todd 1993; Hemmati and Kharrat 2007). In this paper, the saturation pressure and viscosity of heavy oil system with different types of gas including $\mathrm{N}_{2}, \mathrm{CO}_{2}, \mathrm{CO}_{2}-\mathrm{N}_{2}$ mixture at different temperature and gas oil ratio conditions are tested using high temperature and high pressure PVT instrument. Based on the functional relation of Standing formula, the empirical formula with three parameters for Bohai heavy oil system is obtained with multiple regression method and the application effect is good.

\section{Experimental method and procedure}

\section{Experimental equipment and parameters}

The main equipment used in this experiment is high temperature and high pressure heavy oil PVT tester, capillary viscometer, sample distributor, electric high pressure metering pump, constant temperature control system, gas booster pump, gas cylinder $\left(\mathrm{CO}_{2}, \mathrm{~N}_{2}\right.$, mixed gas), high temperature and high pressure piston vessel, precise pressure gauge, etc. Among them, heavy oil PTV tester is composed of PVT host and other auxiliary equipment (Figs. 1 and 2). The indexes of PVT host are as follows.

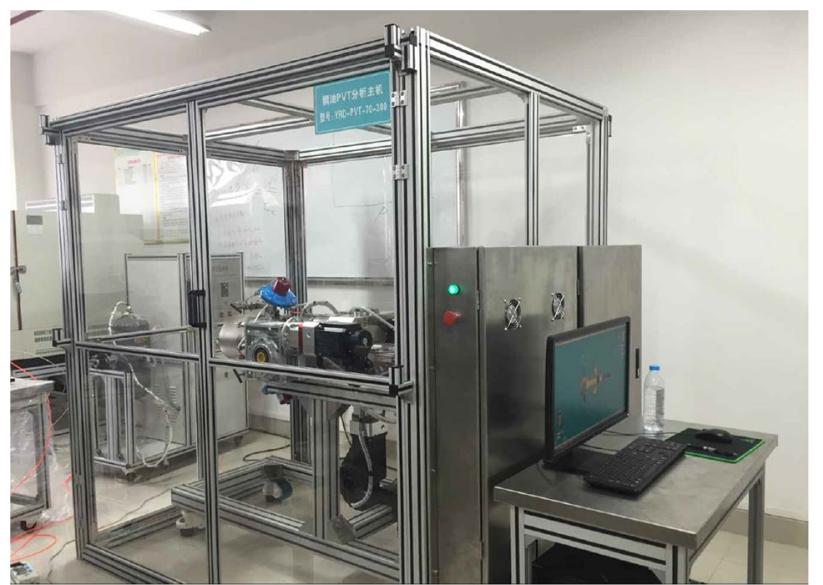

Fig. 1 High temperature and high pressure heavy oil PVT testing equipment

- Temperature regulation range, $0-300{ }^{\circ} \mathrm{C}$, temperature control accuracy $\pm 0.1{ }^{\circ} \mathrm{C}$.

- Pressure testing range, 0-70 MPa, pressure display accuracy $\pm 0.1 \mathrm{MPa}$.

- Volume testing range, $0-300 \mathrm{~mL}$, volume display accuracy $0.01 \mathrm{~mL}$.

Capillary viscometer tests fluid viscosity by testing the flow rate and pressure difference through the capillary tube (Fig. 3). The indexes of capillary viscometer are as follows.

- Pressure testing range, $0-70 \mathrm{MPa}$

- Pressure display accuracy, $0.01 \mathrm{MPa}$

- Temperature testing range, $0-300{ }^{\circ} \mathrm{C}$

- Viscosity range, 0-50000 $\mathrm{mPa} s$ (according to different size of capillary tube)

\section{Experimental method}

At a certain temperature, a certain volume of degassed heavy oil is transferred into the PVT cylinder, and then a certain amount of $\mathrm{N}_{2}, \mathrm{CO}_{2}$ or mixed gas is injected into the PVT cylinder through the intermediate container and fully stirred (sample preparation can also be completed in the sample distributor, and then transferred into the PVT cylinder, Fig. 4). According to the development practice of Bohai heavy oil reservoir, the ratio of $\mathrm{N}_{2}$ and $\mathrm{CO}_{2}$ in multi-thermal fluid is $85 \%: 15 \%$. For each gas content, depressurize at each temperature, then draw the $P-V$ relationship curve between the heavy oil-gas mixture volume $V$ and the pressure $P$. At the same time, calculate the gas oil ratio and other parameters.

After $P-V$ relationship curve test, the samples can be transferred to the capillary viscometer to test the viscosity of heavy oil containing dissolved gas. To avoid the difficulty of sample transfer, the sample can also be prepared in the 
Fig. 2 Heavy oil PVT testing host

Fig. 3 Structure diagram of capillary viscometer

capillary viscometer, in which there are high pressure mixing vessel.

\section{Experiment test results and analysis}

\section{Characteristic analysis of PV relationship curve}

The test results of $\mathrm{PV}$ relationship curve show that in the case of without dissolved gas (Fig. 5), the volume of degassed heavy oil decreases with the increase in pressure and increases with the increase in temperature, and the $P-V$ relationship is nearly linear. In the case of existing dissolved gas, PV test result at the same pressure drop rate is shown in Fig. 6. It is shown that the volume of heavy oil increases with the decrease in pressure, and the curve turns around the saturation pressure point. With the further decrease in pressure, the volume of heavy oil with dissolved gas will deviate from the straight line again. The analysis shows that when the $P-V$ curve first turns, the heavy oil containing gas is in the state of foam oil flow. Foam oil flow is an important cold production mechanism of heavy oil. At the same pressure drop rate, the dissolved gas is released more slowly in the state of foam oil flow than other state. When the $P-V$ curve 
Fig. 4 Fluid sample preparation
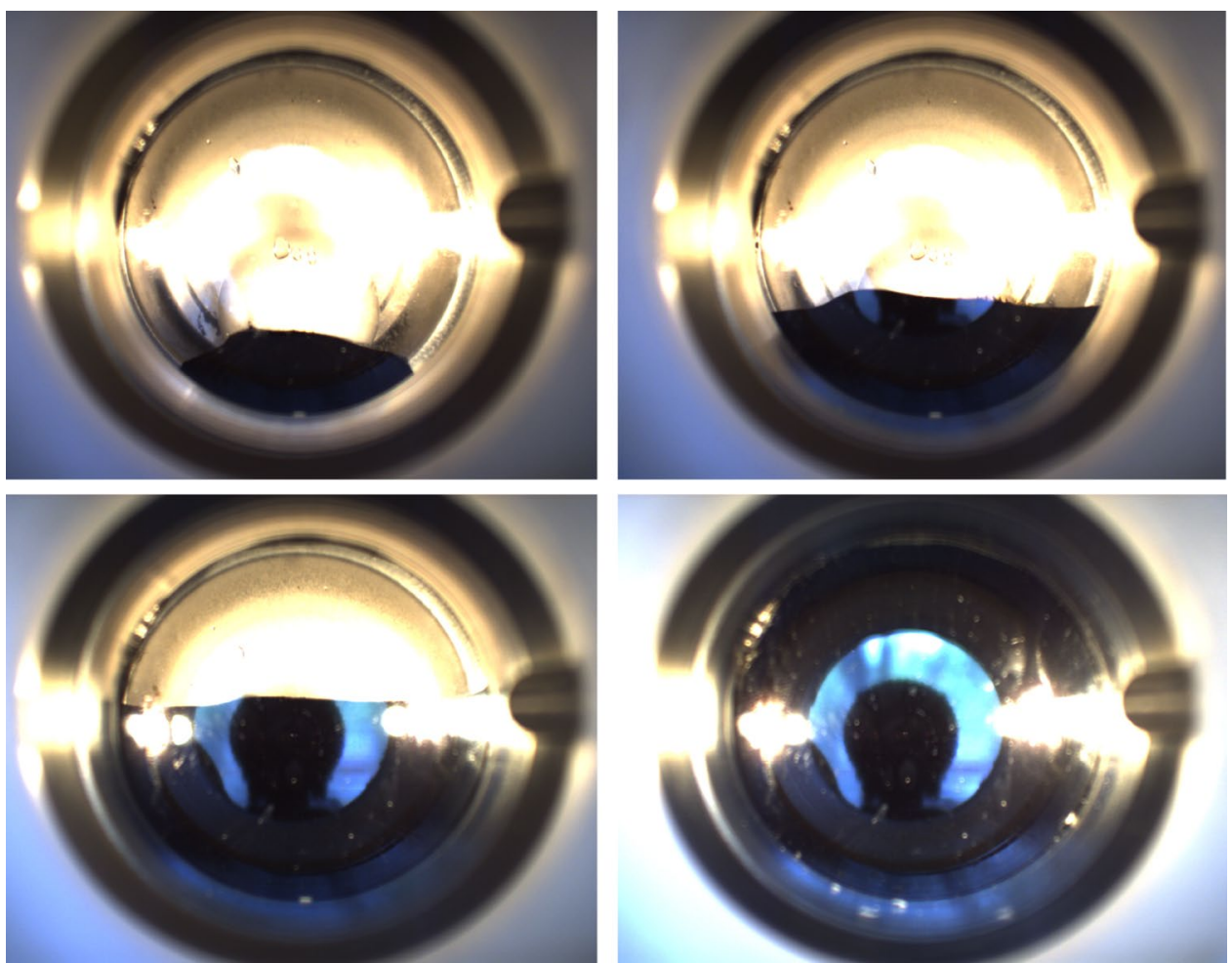

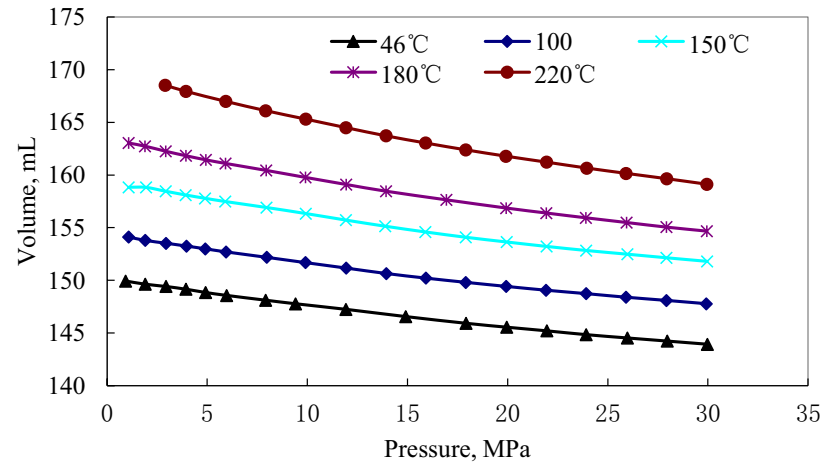

Fig. 5 The PV relationship for heavy oil without dissolved gas

deviates for the second time, the heavy oil containing gas has degassed a lot, so the volume increases rapidly.

\section{Solubility of different gases in heavy oil}

At a certain temperature, transfer a certain volume of degassed heavy oil into the PVT cylinder; add a certain amount of $\mathrm{N}_{2}, \mathrm{CO}_{2}$ or mixed gas with gradually increased gas oil ratio, and stir it fully; test the saturation pressure of each sample at different temperatures, and draw the relationship curve between solubility and saturation pressure (Fig. 7, 8 and Fig. 9).

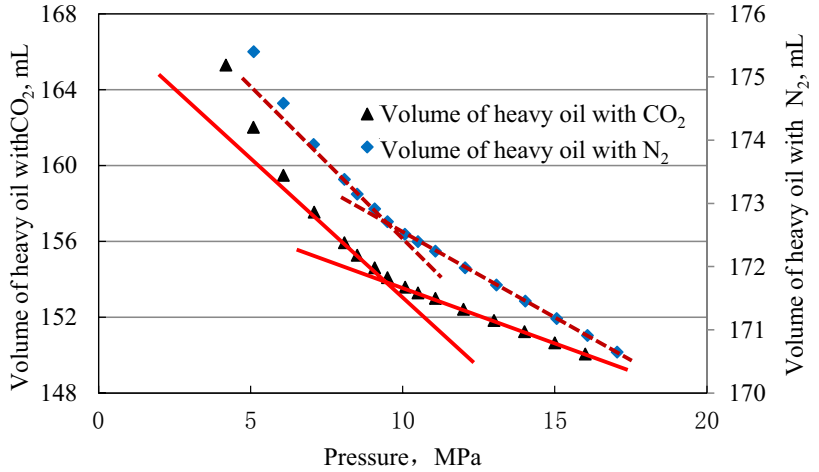

Fig. 6 The PV relationship for heavy oil with dissolved gas $\left(T=46{ }^{\circ} \mathrm{C}\right)$

The test results show that the heavy oil has greater solubility under higher pressure. When the amount of dissolved gas is the same, the higher the temperature is, the greater the saturation pressure is. Under the same pressure and temperature conditions, the solubility of $\mathrm{CO}_{2}>$ mixed gas $>\mathrm{N}_{2}$. The solubility of $\mathrm{CO}_{2}$ is directly proportional to the relative molecular weight of crude oil and is related to the chemical composition of crude oil. $\mathrm{CO}_{2}$ is easy to dissolve in the crude oil with high wax content, but not easy to dissolve in the crude oil with high naphthenic and aromatic hydrocarbon content. Under the conditions of temperature $\left(46^{\circ} \mathrm{C}\right)$ and pressure (9.5 MPa) in Bohai LD reservoir, the solubility of 


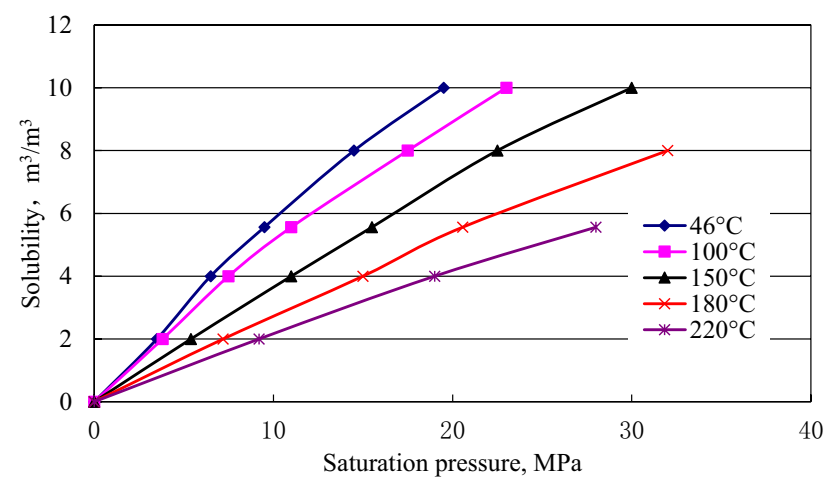

Fig. 7 The solubility test results of $\mathrm{N}_{2}$ in heavy oil

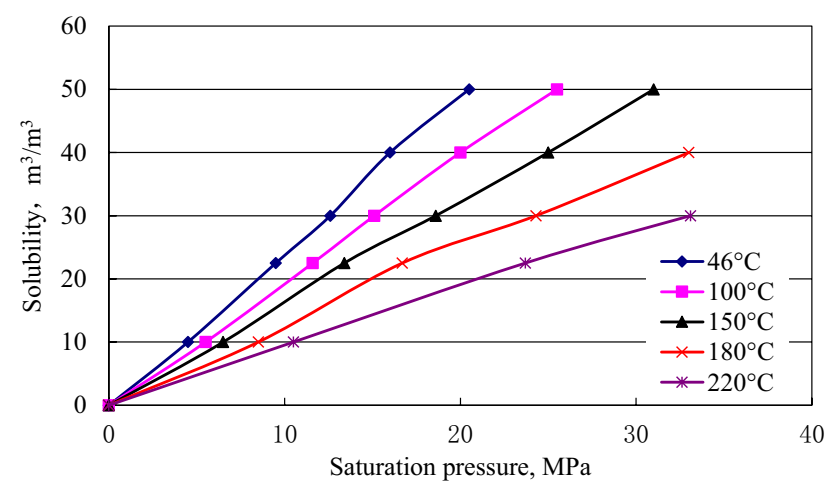

Fig. 8 The solubility test results of $\mathrm{CO}_{2}$ in heavy oil

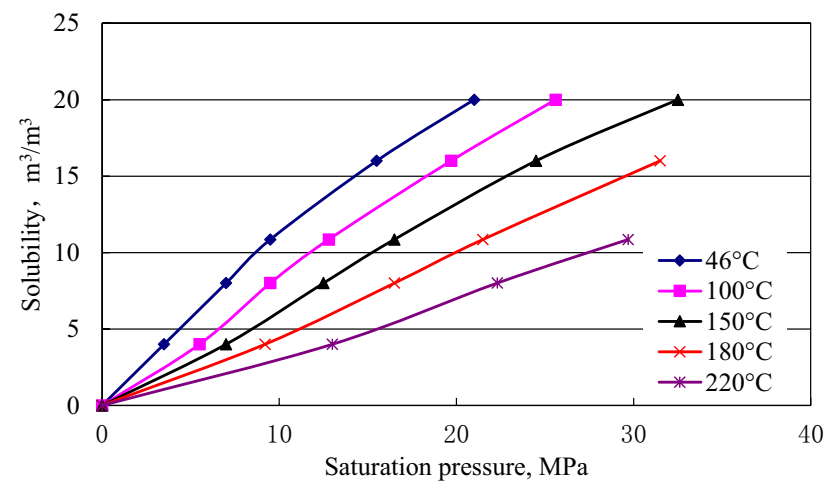

Fig. 9 The solubility test results of mixed gas $\left(85 \% \mathrm{~N}_{2}+15 \% \mathrm{CO}_{2}\right)$ in heavy oil

$\mathrm{CO}_{2}$ is $22.51 \mathrm{~m}^{3} / \mathrm{m}^{3}$, which is significantly higher than that of $\mathrm{N}_{2}$. Although the solubility of mixed gas $\left(85 \% \mathrm{~N}_{2}+15 \%\right.$ $\mathrm{CO}_{2}$ ) $10.86 \mathrm{~m}^{3} / \mathrm{m}^{3}$ is lower than that of $\mathrm{CO}_{2}$, due to good expansibility and large elastic energy of $\mathrm{N}_{2}$ in mixed gas, it can save gas injection amount during oil displacement (Sun 2003). Moreover, $\mathrm{N}_{2}$ is less dissolved in heavy oil, which is beneficial to maintain formation pressure during

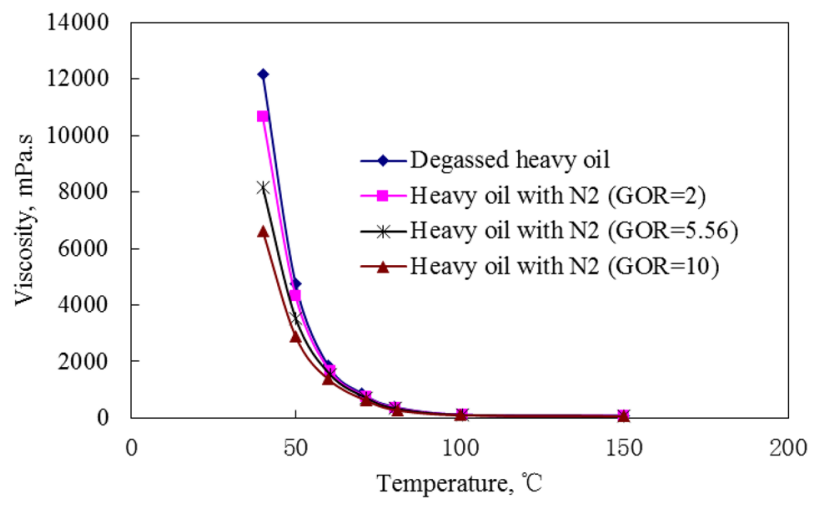

Fig. 10 The viscosity test results of heavy oil with $\mathrm{N}_{2}$

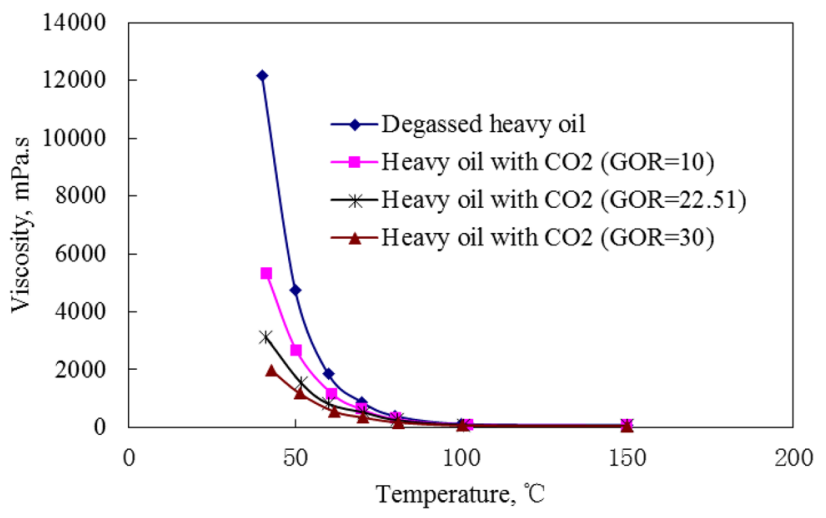

Fig. 11 The viscosity test results of heavy oil with $\mathrm{CO}_{2}$

$\mathrm{N}_{2}$ injection, and therefore mixed gas plays an important role in heavy oil production.

\section{Viscosity of heavy oil containing dissolved gas}

The degassed and dehydrated heavy oil is fully mixed with $\mathrm{N}_{2}, \mathrm{CO}_{2}$ and mixed gas in the high pressure mixing vessel of capillary viscometer. Under different temperatures, according to the tested saturation pressure, the inlet pressure and outlet pressure of the capillary tube are adjusted to make the pressure in the capillary tube be above the saturation pressure, and make the gas-heavy oil mixture be single-phase flow state. After the temperature is stable, the viscosity of the heavy oil with dissolved gas is tested. The viscosities of all samples with different gas oil ratios are tested at different temperatures (Figs. 10, 11, Fig. 12).

The test results show that the viscosity of heavy oil with dissolved gas decreases with the increase in temperature and dissolved gas oil ratio. The viscosity reduction ability of different gases are that $\mathrm{CO}_{2}>$ mixed gas $>\mathrm{N}_{2}$. Under the reservoir temperature $\left(46{ }^{\circ} \mathrm{C}\right)$ and reservoir pressure $(9.5 \mathrm{MPa})$ conditions, the viscosity of heavy oil without dissolved gas is $6718 \mathrm{mPa}$ s. The viscosity of heavy oil with fully saturated $\mathrm{N}_{2}$ 


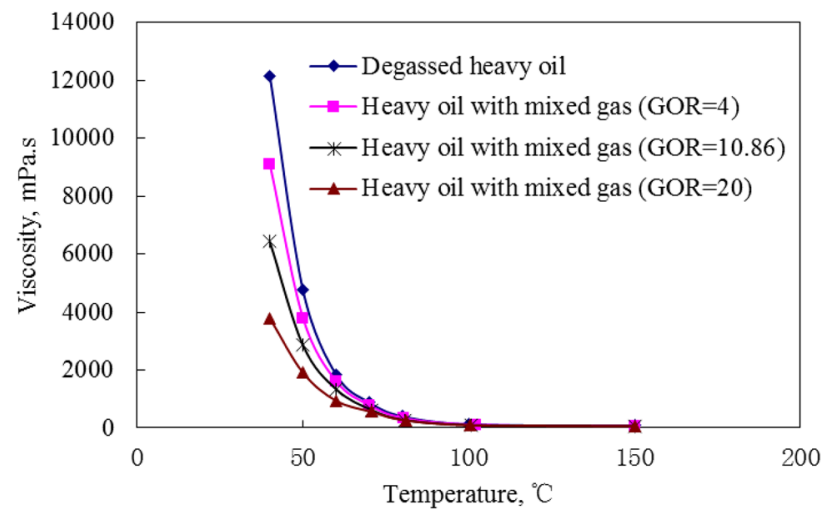

Fig. 12 The viscosity test results of heavy oil with mixed gas $\left(85 \% \mathrm{~N}_{2}+15 \% \mathrm{CO}_{2}\right)$

$\left(5.56 \mathrm{~m}^{3} / \mathrm{m}^{3}\right), \mathrm{CO}_{2}\left(22.51 \mathrm{~m}^{3} / \mathrm{m}^{3}\right)$ and mixed gas $\left(10.86 \mathrm{~m}^{3} /\right.$ $\mathrm{m}^{3}$ ) are $4809 \mathrm{mPa} \mathrm{s}, 2128 \mathrm{mPa}$ s and $3837 \mathrm{mPa}$, with reduction amplitude of $28.42 \%, 68.32 \%$ and $42.88 \%$, respectively.

\section{Analysis of experimental data}

Following formulae are widely used to predict the saturation pressure of oil-gas system.

The Standing (1947) formula

$$
P_{b}=a_{1}\left[\left(\frac{R_{s}}{\gamma_{g}}\right)^{a_{2}} \cdot 10^{a_{3} T-a_{4} \cdot \mathrm{API}}-a_{5}\right]
$$

where, $P_{b}$ is saturation pressure, $\mathrm{psi} ; R_{s}$ is dissolved gas oil ratio, scf/stb; $\gamma_{g}$ is specific gravity of gas (the air is 1 ); $T$ is temperature, ${ }^{\circ} \mathrm{K}$; API is API gravity of oil, ${ }^{\circ}$ API.

The Vasquez and Beggs (1980) formula

$P_{b}=\left[\left(a_{1} \frac{R_{s}}{\gamma_{g s}}\right) \cdot 10^{-a_{3} \frac{\mathrm{API}}{460+T}}\right]^{\frac{1}{a_{2}}}$

$\gamma_{\mathrm{g} s}=\gamma_{\mathrm{g}}\left[1+5.915 \times 10^{-5} T_{\text {sep }} \cdot \mathrm{API} \cdot \lg \frac{P_{\text {sep }}}{114.7}\right]$

where, $T_{\text {sep }}$ is the temperature of separator, ${ }^{\circ} \mathrm{K} ; P_{\text {sep }}$ is the pressure of separator, psi.

The Glaso (1980) formula

$P_{b}=10^{a_{1}+a_{2} \lg G-a_{3}(\lg G)^{2}}$

$G=\left(\frac{R_{s}}{\gamma_{\mathrm{g}}}\right)^{a_{4}} \cdot T^{a_{5}} \cdot \mathrm{API}^{a_{6}}$

The Al-Marhoun (1988) formula

$P_{b}=a_{1} R_{s}^{a_{2}} \gamma_{g}^{a_{3}} \gamma_{o}^{a_{4}}(T+460)^{a_{5}}$

where, $\gamma_{o}$ is the specific gravity of oil (the water is 1 ).

The parameters $a_{1}-a_{6}$ in above formulae are in Table 1.

The application ranges of above formulae are as Table 2 . They are mainly applicable to conventional light oil, and the prediction effect of heavy oil is poor. The test temperature of Bohai heavy oil sample reaches up to $220^{\circ} \mathrm{C}$, which exceeds
Table 1 The parameters in Eqs. (1)-(6)

\begin{tabular}{lllllc}
\hline Parameters & $\begin{array}{l}\text { The standing } \\
\text { formula (1947) }\end{array}$ & $\begin{array}{l}\text { The Vazquez and Beggs } \\
\text { formula (1980) }\end{array}$ & $\begin{array}{l}\text { The Glaso for- } \\
\text { mula (1980) }\end{array}$ & $\begin{array}{l}\text { The Al-Marhoun } \\
\text { formula (1988) }\end{array}$ \\
\cline { 3 - 4 } & API $\leq 30$ & API $>30$ & & \\
\hline$a_{1}$ & 18.2 & 27.64 & 56.06 & 1.7669 & 0.00538088 \\
$a_{2}$ & 0.83 & 1.0937 & 1.187 & 1.7447 & 0.715082 \\
$a_{3}$ & 0.00091 & 11.172 & 10.393 & 0.30218 & -1.877840 \\
$a_{4}$ & 0.0125 & & & 0.816 & 3.143700 \\
$a_{5}$ & 1.4 & & & 0.172 & 1.326570 \\
$a_{6}$ & & & -0.989 & \\
\hline
\end{tabular}

Table 2 Application ranges of different formulae

\begin{tabular}{lcccc}
\hline Application ranges & $\begin{array}{l}\text { The standing } \\
\text { formula (1947) }\end{array}$ & $\begin{array}{l}\text { The Vazquez and Beggs } \\
\text { formula (1980) }\end{array}$ & $\begin{array}{l}\text { The Glaso for- } \\
\text { mula (1980) }\end{array}$ & $\begin{array}{c}\text { The Al-Marhoun } \\
\text { formula (1988) }\end{array}$ \\
\hline$B_{o}(\mathrm{bbl} / \mathrm{stb})$ & $1.0240-2.150$ & $1.028-2.226$ & $1.032-2.588$ & $1.032-1.997$ \\
$T\left({ }^{\circ} \mathrm{F}\right)$ & $100-258$ & $75-294$ & $80-280$ & $74-240$ \\
$R_{s}(\mathrm{scf} / \mathrm{stb})$ & $20-1425$ & $0-2199$ & $90-2637$ & $26-1602$ \\
$\mathrm{API}^{\circ}$ & $16.5-63.8$ & $15.3-59.3$ & $22.3-48.1$ & $19.4-44.6$ \\
$\gamma_{g}$ & $0.59-0.95$ & $0.65-1.28$ & $0.65-1.276$ & $0.75-1.367$ \\
$P_{b}(\mathrm{psi})$ & $130-7000$ & $15-6055$ & $165-7142$ & $130-3573$ \\
\hline
\end{tabular}


the application range of above formula. The errors between the formula calculation results and the tested data reach up to more than $80 \%$. Due to different composition of oil and gas, above calculation formulae of saturation pressure cannot be easily extended to other oilfields, nor can it be arbitrarily used for heavy oil, but should be modified. According to the regression analysis of experiment data, the proper formula can be obtained.

The above formulae all show the rules that the saturation pressure $P_{b}$ increases with the increase in gas oil ratio $R_{s}$ and temperature T. Petrosky and Farshad (1993), Omar and Todd (1993), Hemmati and Kharrat (2007) have improved the formula of Standing (1947). The functional relation of improved formula is the same as the original formula, but the coefficient of the formula has changed, and the fitting effect is good.

In Figs. 7, 8 and 9, the experimental data have different curve series. Based on the functional relation of Standing formula, if a single curve is fitted, i.e., only the relationship between dissolved gas oil ratio $R_{s}$ and saturation pressure $P_{b}$ is fitted, the equation with two parameters can be used:

$P_{b}=a_{1} R_{s}^{a_{2}}$

where, $P_{b}$ is saturation pressure, $\mathrm{MPa} ; R_{s}$ is dissolved gas oil ratio, $\mathrm{m}^{3} / \mathrm{m}^{3} ; a_{1}, a_{2}$ are fitting parameters.

If a series of curves for the same gas at different temperatures are fitted, the equation with three parameters can be used. According to the basic characteristics of the Standing formula, the following formula is used to fit the experiment data of Bohai heavy oil.

$P_{b}=a_{1} R_{s}^{a_{2}} \cdot 10^{a_{3} T}$

where, $T$ is temperature, ${ }^{\circ} \mathrm{C} ; a_{3}$ is fitting parameter.

To fit all the curves for different gas types at different temperatures and different gas oil ratios, the following equation with four parameters can be used:

$P_{b}=a_{1} R_{s}^{a_{2}} \cdot 10^{a_{3} T-a_{4} \rho_{g}}$

where, $\rho_{g}$ is relative density of dissolved gas, which are, respectively, 1.5172, $0.9655,1.0483$ for $\mathrm{CO}_{2}, \mathrm{~N}_{2}$ and mixed gas; $a_{4}$ is fitting parameter.

Taking $\mathrm{CO}_{2}$-heavy oil systems as examples, two-parameter equations are fitted for each curve at $46{ }^{\circ} \mathrm{C}, 100{ }^{\circ} \mathrm{C}$, $150{ }^{\circ} \mathrm{C}, 180{ }^{\circ} \mathrm{C}, 220^{\circ} \mathrm{C}$, and five equations are obtained, respectively:

$P_{b}=0.5219 R_{s}^{0.9339}, P_{b}=0.6166 R_{s}^{0.9454}, P_{b}=0.6710 R_{s}^{0.9769}$, $P_{b}=0.8752 R_{s}^{0.9736}, P_{b}=0.9612 R_{s}^{1.036}$

Each equation is applicable to corresponding temperature. The values of $R^{2}$ are $0.9993,0.9992,0.9979,0.9907$ and 0.9990, respectively (Fig. 13).

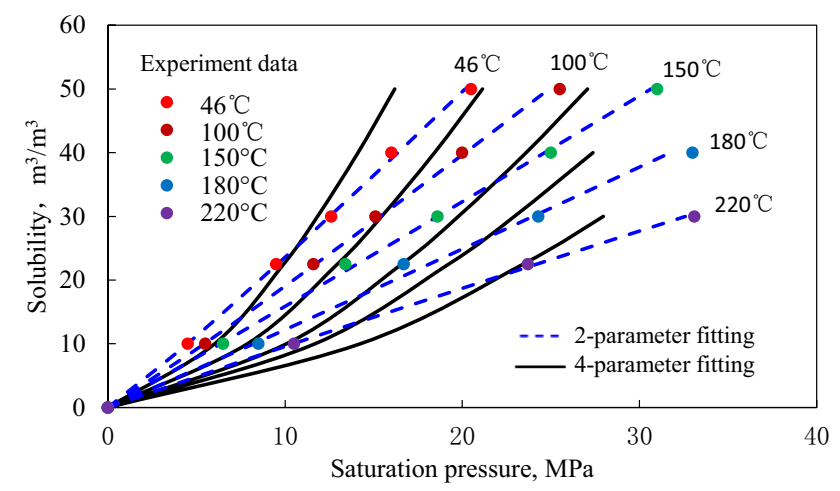

Fig. 13 The 2-parameter and 4-parameter curve fitting for $\mathrm{CO}_{2}$-heavy oil system

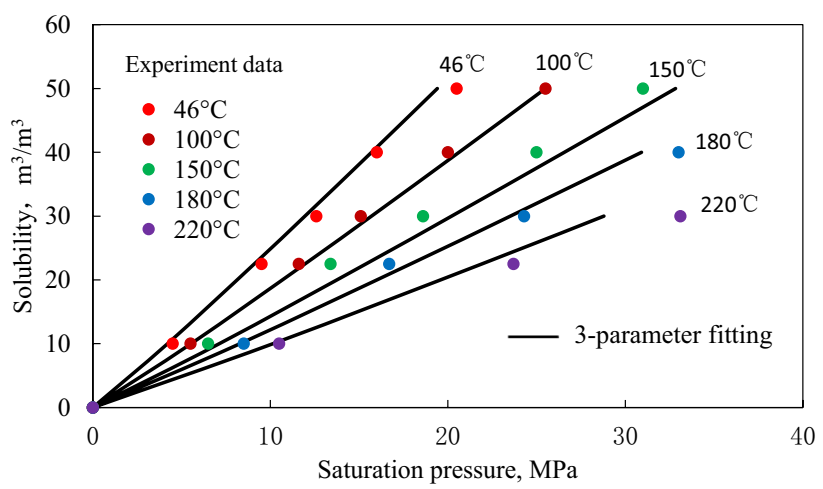

Fig. 14 The 3-parameter curve fitting for $\mathrm{CO}_{2}$-heavy oil system

A series of curves for $\mathrm{CO}_{2}$-heavy oil system at 5 temperatures $\left(46^{\circ} \mathrm{C}, 100{ }^{\circ} \mathrm{C}, 150{ }^{\circ} \mathrm{C}, 180^{\circ} \mathrm{C}, 220^{\circ} \mathrm{C}\right)$ are fitted and three-parameter equation is obtained with multiple regression method.

$P_{b}=0.3751 R_{s}^{0.9494} \cdot 10^{0.002195 T}$

The equation can be applied to predict the saturation pressure $P_{b}$ of $\mathrm{CO}_{2}$-heavy oil system under different dissolved gas oil ratios and different temperatures. The values of $R^{2}$ is 0.9863 (Fig. 14). If the functional relation of Glaso (1980) formula is used, the regression equation is $P_{b}=0.07164 R_{s}^{0.9283} \cdot T^{0.5027}\left(R^{2}=0.9539\right)$, whose fitting effect is worse than Eq. (10).

Similarly, the fitting formula of saturated pressure for $\mathrm{N}_{2}$-heavy oil system can also be obtained:

$P_{b}=1.09512 R_{s}^{1.0832} \cdot 10^{0.002579 T}$

where, the values of $R^{2}$ is 0.9819 .

The fitting formula of saturation pressure for mixed gas-heavy oil system: 
$P_{b}=0.7599 R_{s}^{0.9408} \cdot 10^{0.002742 T}$

where, the values of $R^{2}$ is 0.9859 .

All the curves including $\mathrm{CO}_{2}$-heavy oil, $\mathrm{N}_{2}$-heavy oil and mixed gas-heavy oil systems at different temperatures and different dissolved gas oil ratios are fitted with four-parameter equation, which is

$P_{b}=2.0794 R_{s}^{0.6140} \cdot 10^{0.002147 T-0.1652 \rho_{g}}$

The equation can be used to predict the saturation pressure of different gas types under different dissolved gas oil ratios and different temperatures. However, the fitting accuracy is relatively low, with $R^{2}$ value of 0.7207 (Fig. 13).

Comprehensive analysis results show that the 2-parameter equation can almost completely fit the experimental data, but its application scope is narrow, and it needs to fit individual equation for each curve. The 4-parameter equation can be used to predict the saturation pressure of different gas types under different dissolved gas oil ratio and different temperature, but its fitting accuracy is poor. The 3-parameter equation can not only better fit the saturation pressure of heavy oil for the same gas under different dissolved gas oil ratios and different temperatures, but also has a wide application range. It is recommended to use the 3-parameter equation for saturation pressure analysis and calculation of heavy oil.

Similar to the equation of saturation pressure, the threeparameter viscosity calculation equation of heavy oil with dissolved gas can be written as

$\mu=a_{1} R_{s}^{a_{2}} \cdot e^{a_{3} / T}$

For $\mathrm{N}_{2}$-heavy oil system, the fitting formula of viscosity is

$\mu=13.467 R_{s}^{-0.1650} \cdot e^{281.014 / T}$

where, the value of $R^{2}$ is 0.9696 .

For $\mathrm{CO}_{2}$-heavy oil system, the fitting formula of viscosity is

$\mu=40.074 R_{s}^{-0.4636} \cdot e^{252.356 / T}$

where, the value of $R^{2}$ is 0.9642 .

For mixed gas-heavy oil system, the fitting formula of viscosity is

$\mu=20.239 R_{s}^{-0.2741} \cdot e^{266.698 / T}$

where, the value of $R^{2}$ is 0.9649 .

On the whole, the 3-parameter equation can well fit the viscosity of heavy oil for the same gas under different dissolved gas oil ratios and different temperatures, and it has a wide range of application (Fig. 15). It is recommended to use the 3-parameter equation for viscosity fitting. At

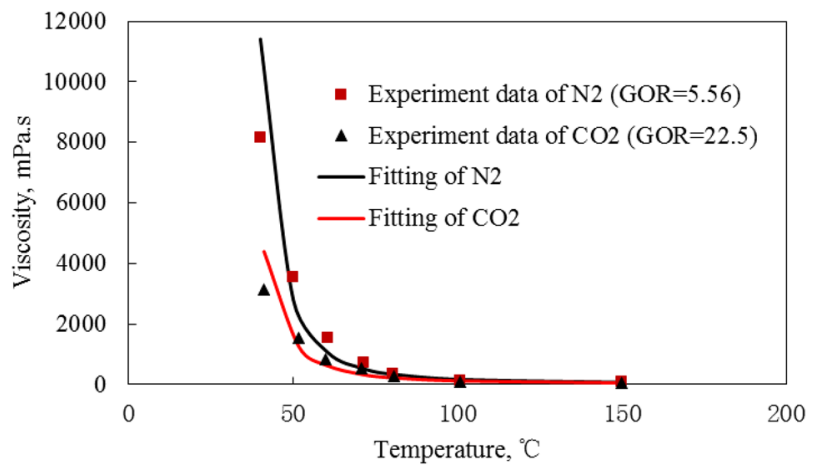

Fig. 15 The 3-parameter curve fitting for heavy oil with dissolved gas

a certain temperature, according to the saturation pressure, the dissolved gas oil ratio $R_{s}$ can be calculated with Eq. (10)-(12), and then the viscosity of heavy oil can be predicted with Eq. (15)-(17). The research results provide a basis for the accurate prediction of heavy oil PVT parameters.

\section{Conclusions}

1. The Bohai heavy oil has obvious characteristics of foam oil, whose dissolved gas is released slowly below the saturation pressure. Generally, the dissolved gas oil ratio of Bohai heavy oil is low and the viscosity is high. The dissolving and viscosity reduction ability of Bohai heavy oil are influenced by the factors including pressure, temperature and gas types.

2. Although the widely used empirical formulas have a certain application scope, they are obtained from regression analysis of specific samples and cannot be arbitrarily applied to heavy oil reservoirs. Keeping the functional relation of empirical formula unchanged, but the coefficient is fitted according to actual test data, the application effect can be improved.

3. Based on the functional relation of Standing formula, the empirical equations of saturation pressure and viscosity for Bohai heavy oil were regressed. The results show that the 2-parameter equation can almost completely fit the experimental data, but its application scope is narrow. Although the 4-parameter equation has an extensive adaptability, its fitting accuracy is very low. The 3 -parameter equation can not only better fit the saturation pressure and viscosity of heavy oil for the same gas under different dissolved gas oil ratios and different temperatures, but also has a wide application range. It is recommended to use the 3-parameter equation. 
Funding The authors thank National Science and Technology Major Projects (2016ZX05058-003-017), Chongqing Natural Science Foundation Project (cstc2019jcyjmsxmX0331, cstc2019jcyj-zdxmX0032) for supporting this work.

Open Access This article is licensed under a Creative Commons Attribution 4.0 International License, which permits use, sharing, adaptation, distribution and reproduction in any medium or format, as long as you give appropriate credit to the original author(s) and the source, provide a link to the Creative Commons licence, and indicate if changes were made. The images or other third party material in this article are included in the article's Creative Commons licence, unless indicated otherwise in a credit line to the material. If material is not included in the article's Creative Commons licence and your intended use is not permitted by statutory regulation or exceeds the permitted use, you will need to obtain permission directly from the copyright holder. To view a copy of this licence, visit http://creativecommons.org/licenses/by/4.0/.

\section{References}

Al-Marhoun MA (1988) PVT correlations for Middle East crude oils. J Petrol Technol 40(5):650-666

Chen J, Lang X, Wang Y et al (2018) Comparative evaluation of different non-condensable gases on thermal behaviors, kinetics, high pressure properties, and product characteristics of heavy oil. Energy Convers Manag 162:13-25

Dong X, Liu H, Zhang Z et al (2014) The flow and heat transfer characteristics of multi-thermal fluid in horizontal wellbore coupled with flow in heavy oil reservoirs. J Petrol Sci Eng 122:56-68

Dong X, Liu H, Zhang Z et al (2016) Multi-thermal fluid assisted gravity drainage process to enhance the heavy oil recovery for the post-SAGD reservoirs. In: SPE annual technical conference and exhibition, 26-28 September, Dubai, UAE, SPE-181479-MS

Fattah KA (2014) Gas-oil ratio correlation (RS) for gas condensate using genetic programming. J Pet Explor Prod Technol 4:291-299

Ge T, Pang Z, Luo C et al (2019) Experimental study on multi-thermal fluid flooding by using horizontal wells in offshore heavy oil reservoirs. Pet Geol Recovery Effic 26(4):62-69 (in Chinese)

Glaso O (1980) Generalized pressure-volume-temperature correlations. J Petrol Technol 32(5):785-795

Hemmati MN, Kharrat R (2007) A correlation approach for prediction of crude oil PVT properties. In: SPE middle east oil and gas show and conference, 11-14 March, Manama, Bahrain, SPE-104543-MS

Hou J, Wei B, Du Q et al (2016) Production prediction of cyclic multithermal fluid stimulation in a horizontal well. J Petrol Sci Eng 146:949-958

Huang S, Cao M, Cheng L et al (2018) Experimental study on the mechanism of enhanced oil recovery by multi-thermal fluid in offshore heavy oil. Int J Heat Mass Transf 122:1074-1084
Izurieta AJ, Iza A (2017) The PVT properties of the Ecuadorian crude oils. In: SPE Latin America and Caribbean petroleum engineering conference, 17-19 May, Buenos Aires, Argentina, SPE-185483-MS

Li Z, Wang Y, Li B et al (2010) Dissolubility of flue gas in super-heavy oil. Spec Oil Gas Reserv 17(5):84-86 (in Chinese)

Li S, Li Z, Sun X (2017) Effect of flue gas and n-hexane on heavy oil properties in steam flooding process. Fuel 187:84-93

Liu Y, Yang H, Zhao L et al (2010) Improve offshore heavy oil recovery by compound stimulation technology involved thermal, gas and chemical methods. In: Offshore technology conference, 3-6 May, Houston, Texas, USA, OTC-20907-MS

Liu D, Zhao C, Su Y et al (2012) New research and application of high efficient development technology for offshore heavy oil in China. In: Offshore technology conference, 30 April-3 May, Houston, Texas, USA, OTC-23015-MS

Liu Y, Zou J, Meng X et al (2020) Experimental study on horizontalwell multi-thermal fluid stimulation process in offshore heavy oil reservoirs. J Pet Explor Prod Technol (online)

Nourozieh H, Kariznovi M, Abedi J (2016) Measurement and modeling of solubility and saturated-liquid density and viscosity for methane/Athabasca-bitumen mixtures. SPE J 2(1):180-189

Omar MI, Todd AC (1993) Development of new modified black oil correlations for Malaysian crudes. In: SPE Asia Pacific oil and gas conference, 8-10 February, Singapore, SPE-25338-MS

Petrosky GE, Farshad F (1993) Pressure-volume-temperature correlations for Gulf of Mexico crude oils. In: SPE annual technical conference and exhibition, 3-6 October, Houston, Texas, SPE-26644-MS

Rammay MH, Abdulraheem A (2017) PVT correlations for Pakistani crude oils using artificial neural network. J Pet Explor Product Technol 7:217-233

Sidrouhou HM, Korichi M (2013) Empirical and correlative study of PVT proprieties of Algerian oil. Energy Procedia 36:738-745

Standing MB (1947) A pressure-volume-temperature correlation for mixtures of California oils and gases. Drilling and Production Practice, 1 January, New York, New York, API-47-275

Sun D (2003) Study and application of injection nitrogen into wells for increasing oil production technology. Fault Block Oil Gas Field 10(5):61-62 (in Chinese)

Sun Y, Zhao L, Lin T et al (2011) Enhance offshore heavy oil recovery by cyclic steam-gas-chemical co-stimulation. In: SPE heavy oil conference and exhibition, 12-14 December, Kuwait City, Kuwait, SPE-149831-MS

Vasquez M, Beggs HD (1980) Correlations for fluid physical property prediction. J Pet Technol 32(6):968-970

Wang Z, Li Z, Lu T et al (2019) Visualization and mechanism analysis of the flue gas action on steam chamber. Spec Oil Gas Reserv 26(2):136-140 (in Chinese)

Publisher's Note Springer Nature remains neutral with regard to jurisdictional claims in published maps and institutional affiliations. 